\title{
Regulator seeks to tackle 'climate of fear' among new dentists
}

\author{
By Adrian O’Dowd
}

$\mathrm{N}$ ewly qualified dentists and dental students are beginning their careers in what some consider to be a 'climate of fear' of patient complaints, litigation and investigation by the dental regulator, it has been claimed.

Several members of an audience raised the issue during a General Dental Council (GDC) conference held on 30 January 2019 at which it launched a 'state of the nation' report $^{1}$ called Moving Upstream, which contains a taste of some specific work being done by the GDC to address the problem.

The report itself acknowledges the issue, saying: 'Many students tell us that they enter working life experiencing a 'climate of fear'. They report many sources of information that may be contributing to this - social media, indemnity providers, peers and indeed some educators and trainers.

'Practising within this climate is unlikely to support the positive qualities society wants to see in its healthcare professionals, including openness, honesty and candour. Our message is clear: no dental professional who understands their obligations to patients and the public, and takes them seriously, should have anything to fear from regulation.'

The regulator launched a student engagement pilot last year which delivered bespoke and interactive content to predominantly dental and some DCP students in the first term of their first year at seven UK education institutions.

This pilot ended in January 2019 and has not yet been reported on, but the theme of fear of going into practice was noted during the pilots and was also discussed during the conference on 30 January 2019.

This programme of student engagement will be rolled out more widely this year as part of the GDC's ambition to revise perceptions of the purpose and nature of regulation in coming generations of dental professionals, said the regulator.

During a panel session on the subject of pre${ }^{-}$paredness to practise during the conference,
Jay Joshi, member of the BDA's Young Dentists Committee, said: 'Among undergraduates and new dentists there is a climate of fear. They are very scared of doing something wrong and they are scared of complaints.

'Most new graduates are practising dentistry with the fear of a complaint rather than thinking what is best for the patient.'

Audience member Vijay Sudra from the Birmingham Local Dental Committee, said:

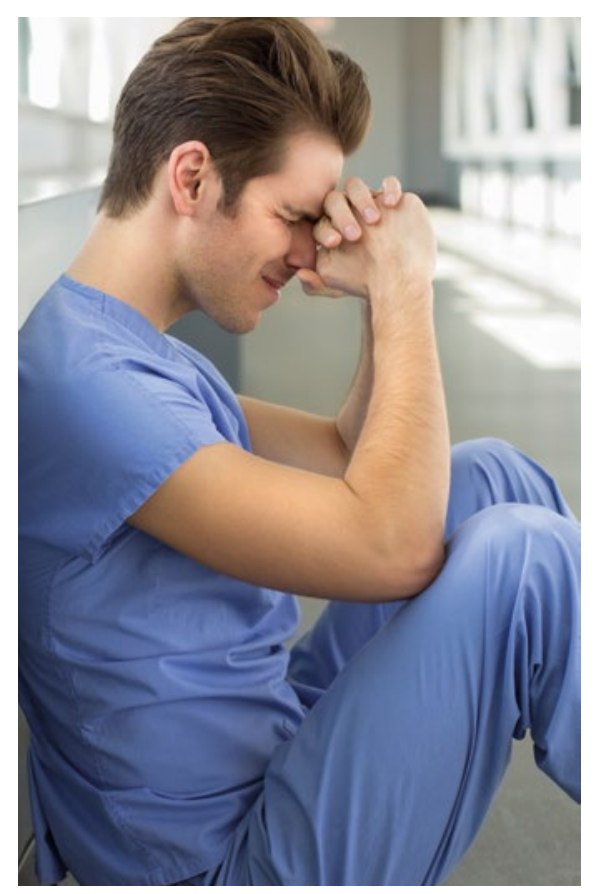

'I have been a foundation dentist trainer over a decade now and something I have seen in that short period of time is that the foundation dentists are fearful of litigation, fearful of the regulator, and feel that they are fodder for the no-win, no-fee lawyers.

'Something needs to be done about that. Patients are losing out here because we have got very bright young graduates who are fearful. Very competent dentists spend more time writing notes than actually doing the clinical work and the loser there is the patient.'

Eddie Crouch, Deputy Chair of the BDA's

Principal Executive Committee, said during a different panel discussion held at the conference: 'It is truly shocking to hear that students need resilience training to enable them to overcome fear of treating patients in clinics and the professions need to be reassured that it shouldn't resort to defensive dentistry. It's not good for patients and in the long run, it deskills the profession.

'It's good that the GDC now seems to recognise that sometimes professionals make mistakes and that anyone who takes that seriously should have nothing to fear from the regulator. These are fine words and we now need actions to back that up.

During another panel session on future opportunities and challenges in dentistry, Alice Duke who works in oral and maxillofacial surgery at Queen Victoria Hospital NHS Foundation Trust, West Sussex, said: 'It's interesting, this fear among young, newly qualified dentists at the moment of the GDC, which to some extent, was imparted for me from my foundation training.

'It was during my foundation year I was told that unless my notes were absolutely perfect that I could be held up to a Fitness to Practise case. I'd say that being a member of the BDA is important. For me as a young dentist, I know they have the knowledge from the generations above me and I can learn from them.'

In his closing speech at the conference, GDC Chief Executive Ian Brack said: 'We can deal and are dealing with the factual issues which help to inform concern or fear about being involved with us, but it's much harder for us to deal with the issues that come from legend, or rumour or ignorance about what we're doing. We can do our best on that and talk to people and we do, but we need your help with that.'

\section{References}

General Dental Council. Moving Upstream. 2019 Available at https://www.gdc-uk.org/about/whatwe-do/shifting-the-balance/moving-upstream (accessed February 2019). 